\title{
Inorganic anions induce state changes in spinach thylakoid membranes
}

\author{
Anjana Jajoo ${ }^{\mathrm{a}, *}$, Sudhakar Bharti ${ }^{\mathrm{a}}$, Govindjee ${ }^{\mathrm{b}}$ \\ ${ }^{a}$ School of Life Sciences, Vigyan Bhavan, Khandwa Road Devi Ahilya University, Indore 452001 (M.P.), India \\ ${ }^{\mathrm{b}}$ Department of Plant Biology, 265 Morrill Hall, MC-116, 505 South Goodwin Avenue, Urbana, IL 61801-3707, USA
}

Received 22 July 1998

\begin{abstract}
The role of cations in excitation energy distribution between the two photosystems of photosynthesis is well established. This paper provides evidence, for the first time, for an important role of anions in the regulation of distribution of absorbed light energy between the two photosystems. Inorganic anions caused redistribution of energy more in favour of photosystem I, as judged from measurements of chlorophyll $a$ fluorescence transients, rates of electron transport in low light and $77 \mathrm{~K}$ fluorescence emission spectra: the Fv/Fm ratio was decreased by inorganic anions even in the presence of DCMU, the PS II electron transport was decreased whereas PS I electron transport was increased and the F735 (77 K emission from PS I)/ F685 ( $77 \mathrm{~K}$ emission from PS II) ratio was increased. Such changes were observed with inorganic anions having different valencies $\left(\mathrm{Cl}^{-}, \mathrm{SO}_{4}^{2-}, \mathrm{PO}_{4}^{3-}\right)$ : the higher the valency of the inorganic anion, the more the energy transferred towards PS I. Change in the valency of the inorganic anions thus regulates distribution of absorbed light energy between the two photosystems. However, organic anions like acetate, succinate, and citrate caused no significant changes in the Fv/Fm ratio, and in rates of PS I and PS II electron transport, showing their ineffectiveness in regulating light energy distribution.
\end{abstract}

(C) 1998 Federation of European Biochemical Societies.

Key words: Anion; State change; Valency; Spinach thylakoid

\section{Introduction}

An influence of the ionic environment on the chlorophyll (Chl) $a$ fluorescence yield of isolated chloroplasts has been known for a long time [1]. A link between the distribution of excitation energy and salt levels has been studied intensively and correlated with a number of different parameters, including Chl $a$ fluorescence [2,3]. Extensive work has been done on the effects of monovalent and divalent cations suggesting their role in several primary photoprocesses in thylakoids, with the largest effect on the distribution and redistribution of excitation energy between photosystem (PS) I and PS II [4-8]. At the high concentrations (up to 100-200 mM) of salts used, where cation effects were shown to predominate, Chl $a$ fluorescence yield increased at room temperature. This was interpreted to mean that the excitation energy distribution and redistribution among the two photosystems led to a relative increase in the excitation of highly fluorescent PS II over

*Corresponding author. Fax: (91) (731) 467029.
E-mail: kurnarp $@$ bom4.vsnl.net.in

Abbreviations: Chl, chlorophyll; DCPIP, dichlorophenol indophenol; DCMU, 3-(3,4-dichlorophenyl)-1,1-dimethyl urea; Fo, initial fluorescence, where all $\mathrm{Q}_{\mathrm{A}}$ is oxidised; $\mathrm{Fv}$, variable fluorescence; Fm, maximum fluorescence, where all $\mathrm{Q}_{\mathrm{A}}$ is reduced; PS I, photosystem I; PS II, photosystem II; $\mathrm{Q}_{\mathrm{A}}$, bound plastoquinone that of the weakly fluorescent PS I. All earlier papers thus had interpreted salt effects in terms of only cation effects. A decrease in Chl $a$ fluorescence yield with low concentrations of $\mathrm{NaCl}$ was observed, but it was also interpreted as a $\mathrm{Na}^{+}$induced change [9]; similarly, a $\mathrm{Na}^{+}$-induced decrease (at a concentration of $10 \mathrm{mM}$ ) in the fraction of quanta absorbed by PS II and a slight increase in the efficiency of excitation energy transfer from PS II to PS I was reported [10]. Low concentrations $(<10 \mathrm{mM})$ of monovalent cations were shown to produce an opposite effect to that of $\mathrm{Mg}^{2+}$ or other divalent cations $[11,12]$. However, the role of anions was not recognised. An increase in the proportion of absorbed light energy reaching PS I was caused by prolonged exposure to a sufficient concentration of nitrite ions in the light [13]. An increase in PS I activity (measured as $\mu$ mole oxygen consumed/mg Chl/h) and a decrease in room temperature PS II fluorescence by anions also provided suggestions for a possible role of anions in the regulation of energy distribution between the two photosystems [14].

In this paper, we present data on (1) the room temperature Chl $a$ fluorescence yield as a function of time of illumination, (2) rates of PS I and PS II electron transport and (3) $77 \mathrm{~K}$ emission spectra, showing that at lower concentrations (5-10 $\mathrm{mM}$ ) of salts, the inorganic anions induce changes in thylakoid membranes, which cause redistribution of excitation energy in favour of PS I. We further show that these changes are dependent on the valency of the inorganic anions used.

\section{Materials and methods}

Chloroplasts were isolated from market spinach and suspended in a medium of low ionic strength (100 $\mathrm{mM}$ sucrose, $50 \mathrm{mM}$ HEPES-KOH buffer, $\mathrm{pH}$ 7.6) according to the method of Gross [15]. Separate buffers of each $\mathrm{pH}$ were prepared in order to study $\mathrm{pH}$ dependence of anion effects. MES-KOH buffer ( $\mathrm{pH}$ 5.8-6.4), HEPES-KOH buffer (pH 6.6-8.0) and glycine- $\mathrm{NaOH}$ buffer $(\mathrm{pH} 8.2-8.6)$ were used. Chl $a$ fluorescence induction curves were monitored at room temperature on a fabricated set up which included an excitation light source (Kindermann, intensity $1.2 \times 10^{4} \mathrm{erg} / \mathrm{cm}^{2} / \mathrm{s}$ ), sample chamber with a photodiode (Hansatech), Hansatech transient recorder TR 1 as a storage device, and an oscilloscope (HP 54603 B) for replaying the signal. Two blue filters (Corning CS 4-72) and red filters (Corning CS 2-59, CS 2-64) were used for the excitation and emission lights respectively. Samples received no other light except the blue exciting light. The Fm, the maximum level of Chl $a$ fluorescence, obtained after DCMU treatment $(5 \mu \mathrm{M})$ was only slightly higher than the 'P' level of our control, showing that the light intensity being used was strong enough to reduce most of the primary electron acceptor ' $\mathrm{Q}_{\mathrm{A}}$ ' even in the absence of DCMU, $\mathrm{Q}_{\mathrm{A}}$ being a quencher of Chl $a$ fluorescence [16]. Low temperature fluorescence emission spectra were monitored and autocorrected on a SPEX 1680 double spectrofluorometer. Excitation light was $435 \mathrm{~nm}$ and its intensity was $30 \mathrm{erg} / \mathrm{cm}^{2} / \mathrm{s}$.

\section{Results and discussion}

We determined the concentration dependence of the effects 


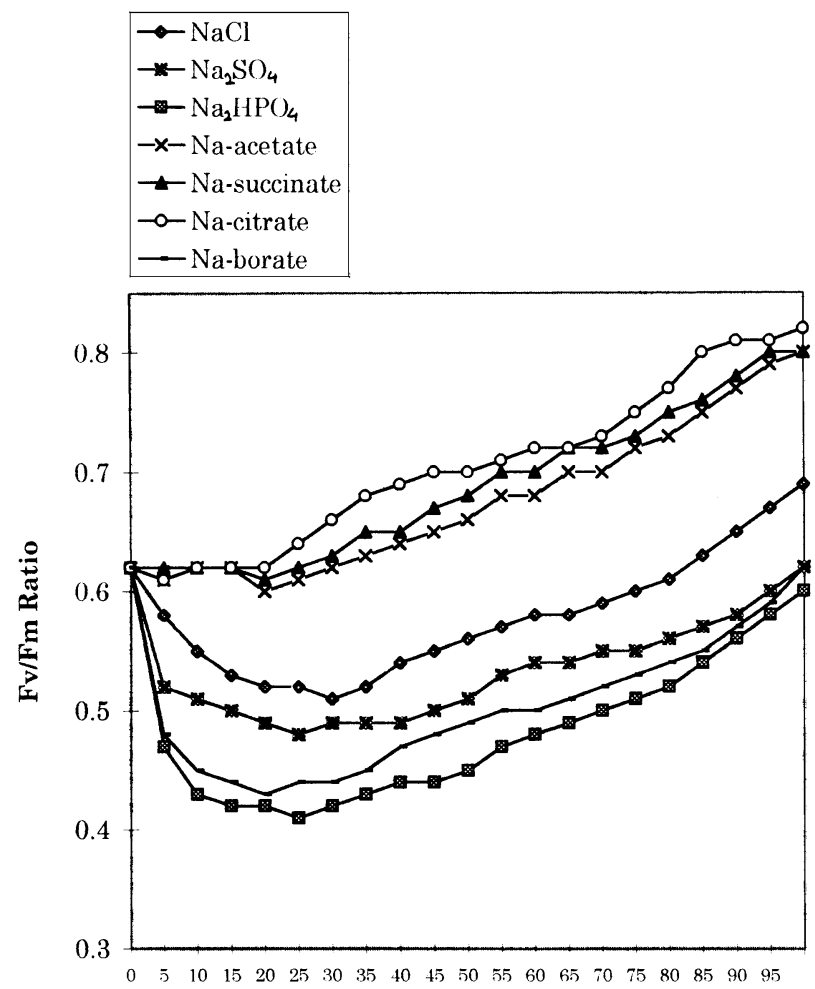

[Anion], mM

Fig. 1. Concentration response of various sodium salts on the ratio of variable (Fv) to maximal $(\mathrm{Fm}) \mathrm{Chl} a$ fluorescence yield in sucrose-washed spinach thylakoids. Thylakoids with $7 \mu \mathrm{g} \mathrm{Chl} / \mathrm{ml}$ were suspended in a reaction mixture containing $100 \mathrm{mM}$ sucrose, 50 mM HEPES-KOH buffer $\mathrm{pH}$ 7.6. After salt treatment samples were incubated in the dark for $5 \mathrm{~min}$ before fluorescence measurements.

of sodium salts, with various anions (chloride, sulphate, borate, acetate, succinate, citrate and phosphate) on the ratio of variable (Fv) to maximal $\mathrm{Chl} a$ fluorescence yields (Fm) (Fig. 1). At all concentrations used, there was a hierarchy in reduction of $\mathrm{Fv} / \mathrm{Fm}$ ratio with $\mathrm{PO}_{4}^{3-}>\mathrm{SO}_{4}^{2-}>\mathrm{Cl}^{-}$. Experiments on the $\mathrm{pH}$ dependence of the anion effects on the $\mathrm{Fv} / \mathrm{Fm}$ ratio demonstrated no significant differences in the $\mathrm{pH}$ range of 6.4-7.8. Organic anions like acetate, succinate and citrate had no significant effect on the Chl $a$ fluorescence yield ratio of the variable $(\mathrm{Fv})$ to maximal $(\mathrm{Fm})$ ratio at low concentrations $(5-20 \mathrm{mM})$, although they did increase this ratio at higher concentrations $(>20 \mathrm{mM}$ ); we suggest that the latter effect is due to increasing cation (sodium) concentration. For further experiments, we chose subsaturating concentration of 10 $\mathrm{mM}$ for $\mathrm{NaCl}, \mathrm{Na}$-acetate and $5 \mathrm{mM}$ for $\mathrm{Na}_{2} \mathrm{SO}_{4}, \mathrm{Na}$-succinate, $\mathrm{Na}_{2} \mathrm{HPO}_{4}, \mathrm{Na}$-borate and Na-citrate $3.3 \mathrm{mM}$ to keep the $\left[\mathrm{Na}^{+}\right]$constant $(10 \mathrm{mM})$ in order to specifically compare the effects of anions. Since a change in Fv/Fm could be due to a change in either Fv, Fo or both, we studied the effect on Fo

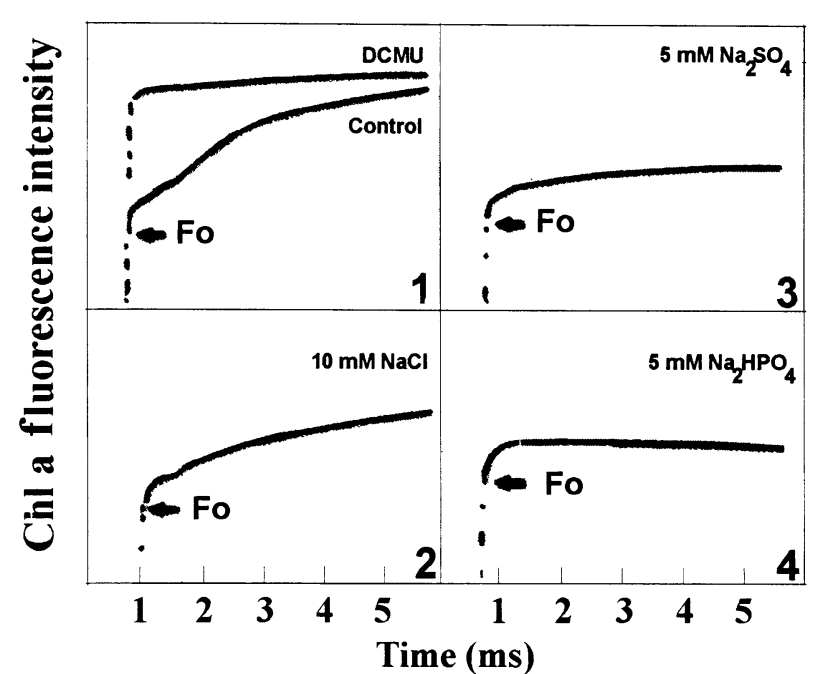

Fig. 2. Effects of various inorganic sodium salts differing in their anion valency on Chl $a$ fluorescence transients. Other details as in the legend of Fig. 1.

and Fv, as Fm equals $\mathrm{Fv}+\mathrm{Fo}$ (see Table 1). It is clear that anions caused a slight increase in $\mathrm{Fo}\left(+4 \%\right.$ for $\mathrm{Cl}^{-},+9 \%$ for $\mathrm{SO}_{4}^{2-}$, and $+13 \%$ for $\mathrm{PO}_{4}^{3-}$ ), but they caused a substantial decrease in $\mathrm{Fv}\left(-22 \%\right.$ for $\mathrm{Cl}^{-},-33 \%$ for $\mathrm{SO}_{4}^{2-}$ and $-42 \%$ for $\mathrm{PO}_{4}^{3-}$ ). It is seen that with increasing valency, there is an increased inhibitory effect on Fv. An increase in Fo may indicate, among other things, a decrease in excitation energy transfer from the PS II antenna to its reaction centre and/or a decrease in the redistribution of excitation energy towards PS I that has a much lower fluorescence yield than PS II. On the other hand, anion-induced decrease in Fv/Fm reflects a decrease in the quantum yield of photochemistry of PS II [17].

Chl $a$ fluorescence induction curves after treatments with $\mathrm{NaCl}, \mathrm{Na}_{2} \mathrm{SO}_{4}$ and $\mathrm{Na}_{2} \mathrm{HPO}_{4}$ are shown in Fig. 2. A remarkable decrease in the so called $\mathrm{P}$ level $(\mathrm{Fm})$ and a slight increase in Fo, the minimum Chl $a$ fluorescence level, are observed as the valency of the anion is increased. Quantitatively different effects of monovalent (10 $\mathrm{mM} \mathrm{NaCl})$, divalent $(5 \mathrm{mM}$ $\left.\mathrm{Na}_{2} \mathrm{SO}_{4}\right)$ and trivalent $\left(5 \mathrm{mM} \mathrm{Na} \mathrm{HPO}_{4}\right)$ anions on the fluorescence transients at room temperature are evident. Although changes in both Fo and Fm were observed with different inorganic anions, the effects on $\mathrm{Fv} / \mathrm{Fm}$ are not solely due to changes in Fo. Inorganic salts show a gradual decrease in $\mathrm{Fv} / \mathrm{Fm}$ ratio with increase in the valency of anions used (Table 1). Since the concentration of sodium was kept constant in all treatments, the effects observed are certainly due to anions. It was earlier shown [6] that the concentration of $\mathrm{Na}^{+}$determines the degree of increase in fluorescence yield. Increased fluorescence yield was observed at $\mathrm{Na}^{+}$concentrations of $100 \mathrm{mM}$ and above. Our results show that at lower salt concentrations $(<10 \mathrm{mM})$, effects of inorganic anions pre-

Table 1

Changes in Chl $a$ fluorescence yield after various anion treatments in spinach thylakoids

\begin{tabular}{llll}
\hline Treatment & Fm & Fo & Fv/Fm \\
\hline Control & $365 \pm 5(100)$ & $137 \pm 2(100)$ & $0.62 \pm 0.02(100)$ \\
$10 \mathrm{mM} \mathrm{NaCl}_{5 \mathrm{mM} \mathrm{Na}} \mathrm{SO}_{4}$ & $320 \pm 4(121)$ & $143 \pm 2(104)$ & $0.55 \pm 0.01(89)$ \\
$5 \mathrm{mM} \mathrm{Na}_{2} \mathrm{HPO}_{4}$ & $302 \pm 4(114)$ & $150 \pm 2(109)$ & $0.50 \pm 0.005(81)$ \\
\hline
\end{tabular}

Other details as in the legend of Fig. 1. Numbers in parentheses give the normalised values. 
Table 2

Effects of various anions on Chl $a$ fluorescence yield in the presence of $5 \mu \mathrm{M}$ DCMU

\begin{tabular}{llll}
\hline Treatment & Fm & Fo & \\
\hline Control & $70 \pm 2(100)$ & $29 \pm 2(100)$ & Fv/Fm \\
$10 \mathrm{mM} \mathrm{NaCl}$ & $55 \pm 2(70)$ & $26 \pm 1(90)$ & $0.58 \pm 0.010(100)$ \\
$5 \mathrm{mM} \mathrm{Na}_{2} \mathrm{SO}_{4}$ & $50 \pm 1(71)$ & $26 \pm 1(90)$ & $0.52 \pm 0.010(90)$ \\
$5 \mathrm{mM} \mathrm{Na}_{2} \mathrm{HPO}_{4}$ & $47 \pm 1(67)$ & $26 \pm 1(90)$ & $0.48 \pm 0.005(83)$ \\
\hline
\end{tabular}

Experiments were carried out at low light intensity, using a neutral density filter (25\% transmittance). Other details as in the legend of Fig. 1. Numbers in parentheses give the normalised values.

dominate in a valency-dependent manner. This is a new and significant finding of this paper. Any change in the valency of the inorganic anions thus profoundly affects the mechanism of distribution and redistribution of excitation energy between the two photosystems.

The yield of fluorescence is regulated by the redox state of the PS II acceptor, $\mathrm{Q}_{\mathrm{A}}$, which is a quencher of fluorescence when in oxidised state [16]. Fluorescence is also quenched if some state change occurs, i.e. there is either a decrease in the ratio of concentrations of highly fluorescent PS II to weakly fluorescent PS I, or an increase in redistribution of more excitation energy into PS I than into PS II $[2,17,18]$. To ascertain the reason for inorganic anion-induced fluorescence quenching, we performed experiments in the presence of dichlorophenyl dimethyl urea (DCMU), when all $\mathrm{Q}_{\mathrm{A}}$ are converted to $\mathrm{Q}_{\mathrm{A}}^{-}$.

Table 2 shows that inorganic anions quench fluorescence even in the presence of $5 \mu \mathrm{M}$ DCMU suggesting that the effects are unrelated to $\mathrm{Q}_{\mathrm{A}}$. PS II reaction centre exists in $\mathrm{Z}^{+} \mathrm{P} 680$ Pheo $\mathrm{Q}_{\mathrm{A}}^{-}$state in the presence of DCMU. If $\mathrm{P} 680^{+}$ was present, PS II would dissipate energy as heat and act as a quencher of fluorescence [19]. However, no P680 ${ }^{+}$exists at the time of our measurement in the system after DCMU treatment. We suggest that inorganic anions cause state changes in the PS II resulting in redistribution of more excitation energy to weakly fluorescent PS I from PS II. This conclusion is confirmed by separate measurements of PS I and PS II electron transfer rates at low light intensities (Table 3). It is evident from the data that inorganic anions enhance PS I rates and inhibit PS II rates at low light intensities. Organic anions like acetate, succinate, citrate (at the low concentrations used) do not seem to regulate energy distribution among the two

Table 3

Effect of various anions on PS II rate (measured as $\mu$ mol oxygen evolved $/ \mathrm{mg} \mathrm{chl} / \mathrm{h}$ ) and PS I rate (measured as $\mu \mathrm{mol}$ oxygen consumed $/ \mathrm{mg} \mathrm{chl} / \mathrm{h})$ in low light intensity $\left(6.0 \times 10^{3} \mathrm{erg} / \mathrm{cm}^{2} / \mathrm{s}\right)$ in spinach thylakoids

\begin{tabular}{lll}
\hline Treatment & PS I rate & PS II rate \\
\hline Control & $240 \pm 5(100)$ & $59 \pm 2(100)$ \\
$10 \mathrm{mM} \mathrm{NaCl}$ & $288 \pm 6(120)$ & $54 \pm 1(95)$ \\
$5 \mathrm{mM} \mathrm{Na}_{2} \mathrm{SO}_{4}$ & $309 \pm 5(129)$ & $49 \pm 2(83)$ \\
$5 \mathrm{mM} \mathrm{Na} \mathrm{HPO}_{4}$ & $329 \pm 7(137)$ & $43 \pm 1(74)$ \\
$5 \mathrm{mM} \mathrm{Na}$ borate & $317 \pm 3(132)$ & $45 \pm 1(76)$ \\
$10 \mathrm{mM} \mathrm{Na}$-acetate & $246 \pm 4(102)$ & $61 \pm 2(103)$ \\
$5 \mathrm{mM} \mathrm{Na}$-succinate & $258 \pm 5(107)$ & $62 \pm 2(105)$ \\
$3.3 \mathrm{mM} \mathrm{Na}$-citrate & $252 \pm 5(105)$ & $60 \pm 2(101)$ \\
\hline
\end{tabular}

Reaction medium for oxygen evolution measurements contains 100 $\mathrm{mM}$ sucrose, $20 \mathrm{mM}$ HEPES-KOH buffer $\mathrm{pH}$ 7.2, $200 \mu \mathrm{M}$ DCPIP and chloroplasts equivalent to $70 \mu \mathrm{g} \mathrm{Chl} / \mathrm{ml}$. Reaction medium for oxygen consumption measurements contains $0.3 \mathrm{M}$ sucrose, $20 \mathrm{mM}$ HEPES-KOH buffer $\mathrm{pH} 7.2,3 \mathrm{mM}$ ascorbate, $100 \mu \mathrm{M}$ DCPIP, $5 \mu \mathrm{M}$ DCMU, $0.1 \mathrm{mM}$ methyl viologen, and $5 \mu \mathrm{M}$ sodium azide, chloroplasts equivalent to $30 \mu \mathrm{g} \mathrm{Chl} / \mathrm{ml}$. photosystems as they fail to show any significant effects on the PS I and PS II electron transport rates and on the Fv/Fm ratio.

Distribution of energy more in favour of PS I by inorganic anions is further confirmed by low temperature $(77 \mathrm{~K})$ fluorescence measurements. Our results show (Fig. 3) that inorganic anions, in a valency-dependent manner, cause significant increases in the ratio of $\mathrm{F} 735$ (originating in PS I) to F685 (originating in PS II) (15\% with $10 \mathrm{mM} \mathrm{NaCl}, 24 \%$ with 5 $\mathrm{mM} \mathrm{Na} \mathrm{SO}_{4}$, and $42 \%$ with $5 \mathrm{mM} \mathrm{Na} \mathrm{HPO}_{4}$ ). This establishes that inorganic anions facilitate redistribution of excitation energy more in favour of PS I. The extent of the increase in the F735/F685 ratio defines the extent of the attainment of state II, the state usually caused by exposure to light absorbed in pigment system II $[2,20,21]$. Inorganic anions cause increased fluidity of the thylakoid membrane [22] which might help in attaining state II. Further experiments are needed to understand the mechanism of the phenomenon discovered in this work.

We have demonstrated in this paper that the state changes are dependent not only on cations as is well known [4-8], but also on certain inorganic anions, in a valency-dependent manner.

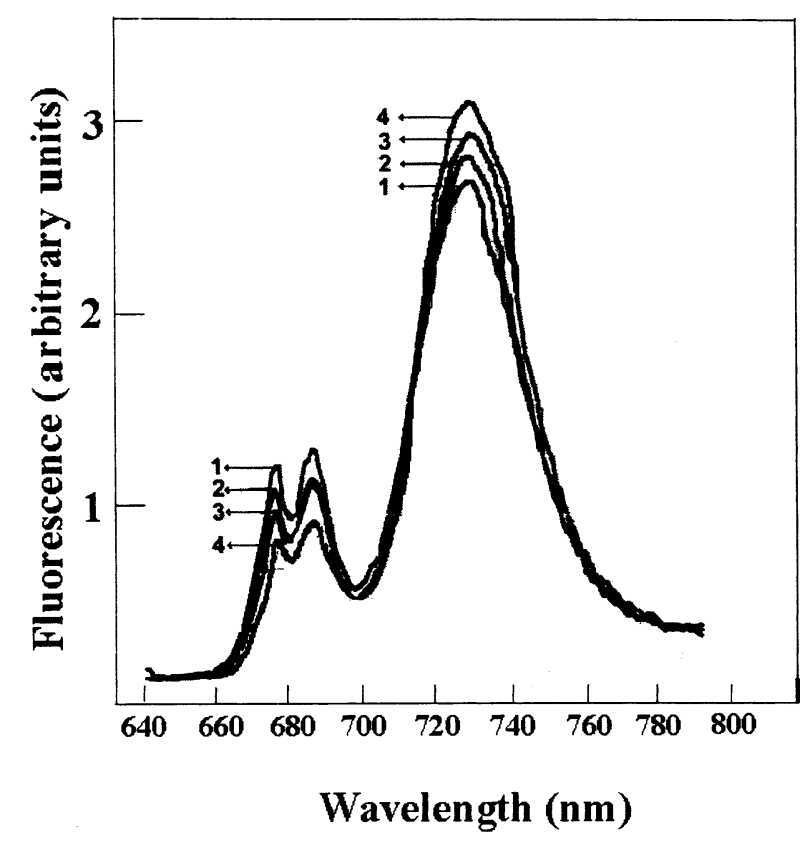

Fig. 3. Normalised fluorescence emission spectra measured at $77 \mathrm{~K}$ in sucrose-washed chloroplasts after various inorganic salt treatments. Samples were kept in the dark for $5 \mathrm{~min}$ before measurements. Excitation light, $435 \mathrm{~nm}$. Thylokoid suspension equivalent to $8 \mu \mathrm{g} / \mathrm{ml}$. $1=$ Control, $2=10 \mathrm{mM} \mathrm{NaCl}, 3=5 \mathrm{mM} \mathrm{Na}_{2} \mathrm{SO}_{4}, 4=5$ $\mathrm{mM} \mathrm{Na} 2 \mathrm{HPO}_{4}$. Spectra were normalised at $710 \mathrm{~nm}$. 
Acknowledgements: The financial support for the project (HR/SY/B02/95) to A.J. by the Department of Science and Technology is thankfully acknowledged. We also thank Drs. P.K. Gupta, Alok Dube (Centre for Advanced Technology), Pradeep K.G. and V. Shinkarev for their help. Govindjee thanks the US Fulbright Foundation for the Lecturer award during 1996-1997.

\section{References}

[1] Homann, P.H. (1996) Plant Physiol. 44, 932-936.

[2] Murata, N. (1969) Biochim. Biophys. Acta 172, 242-251.

[3] Barber, J. (1982) Annu. Rev. Plant Physiol. 33, 261-295.

[4] Wong, D., Merkelo, H. and Govindjee (1979) FEBS Lett. 104, 223-226.

[5] Wong, D. and Govindjee (1979) FEBS Lett. 97, 373-377.

[6] Murata, N. (1971) Biochim. Biophys. Acta 226, 422-432.

[7] Butler, W.L. (1978) Annu. Rev. Plant Physiol. 29, 345-378.

[8] Barber, J. (1986) Photosynth. Res. 10, 243-253.

[9] Wydrzynski, T., Gross, E.L. and Govindjee (1975) Biochim. Biophys. Acta 376, 151-161.

[10] Wong, D., Merkelo, H. and Govindjee (1981) Photochem. Photobiol. 33, 97-101.
[11] Gross, E. and Hess, S.C. (1973) Arch. Biochem. Biophys. 159, 832-836.

[12] Vandermeulen, D.L. and Govindjee (1974) Biochim. Biophys. Acta 368, 61-70.

[13] Sinclair, J. (1987) Photosynth. Res. 12, 255-263.

[14] Jajoo, A. and Bharti, S. (1995) Indian J. Exp. Biol. 33, 67-72.

[15] Gross, E. (1971) Arch. Biochem. Biophys. 147, 77-84.

[16] Duysens, L.N.M. and Sweers, H.E. (1963), in: Microalgae and Photosynthetic Bacteria, pp. 353-372, Japan Soc. Plant Physiol., University of Tokyo Press, Tokyo.

[17] Govindjee (1995) Aust. J. Plant Physiol. 22, 131-160.

[18] Joshi, M.K. and Mohanty, P. (1995) J. Sci. Ind. Res. 54, 155174.

[19] Shinkarev, V.P. and Govindjee (1993) Proc. Natl. Acad. of Sci. USA 90, 7466-7469.

[20] Bonaventura, C. and Myers, J. (1969) Biochim. Biophys. Acta $189,366-383$

[21] Allen, J.F., Bennett, J., Steinback, K.E. and Arntzen, C.J. (1981) Nature 291, 25-29.

[22] Jajoo, A.J., Dube, A. and Bharti, S. (1994) Biochem. Biophys. Res. Commun. 202, 1724-1730. 